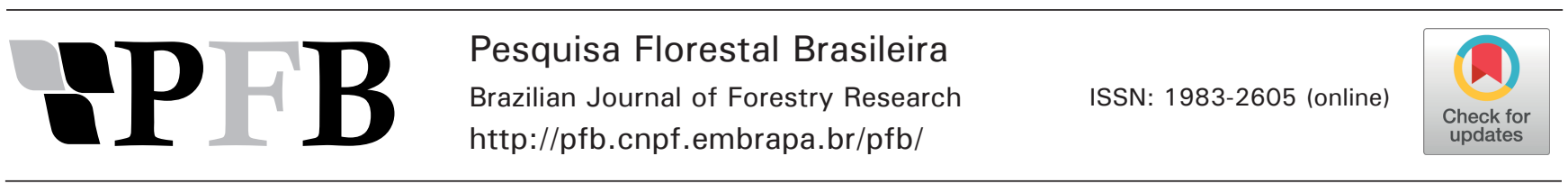

\title{
Uso de biofertilizantes à base de aminoácidos na produção de mudas de Eucalyptus dunnii
}

\author{
Louíse Rickli de Souza ${ }^{1 *}$, Fabiana Schmidt Bandeira Peres ${ }^{1}$
}

${ }^{1}$ Universidade Estadual do Centro-Oeste, Departamento de Engenharia Florestal, PR 153, Km 7, CEP 84500-000, Irati, PR, Brasil

*Autor correspondente:

ricklilouise@gmail.com

Termos para indexação:

Eucalipto

Fertilização orgânica

Viveiro florestal

Index terms:

Eucalyptus

Organic fertilization

Forest nursery

Histórico do artigo:

Recebido em 10/12/2015

Aprovado em 13/07/2016

Publicado em 30/09/2016

doi: $10.4336 / 2016 . p f b .36 .87 .1127$

\begin{abstract}
Resumo - A produção de mudas florestais em quantidade e qualidade é uma das fases mais importantes para o estabelecimento de povoamentos florestais mais uniformes e produtivos. A maior sobrevivência e desenvolvimento das plantas após o plantio é dependente, dentre outros fatores, de um bom estado nutricional das mudas. Este trabalho objetivou avaliar o potencial de utilização de dois biofertilizantes à base de aminoácidos como agentes promotores de crescimento inicial de mudas de Eucalyptus dunnii Maiden, denominados respectivamente como "BIO 1" e "BIO 2". O experimento foi conduzido em viveiro comercial no município de Imbituva, PR. Foi utilizado delineamento inteiramente casualizado, com três tratamentos e 4 repetições, contendo 50 mudas por repetição. As variáveis avaliadas foram: altura da planta, diâmetro do coleto, peso de matéria fresca e seca da parte aérea e raízes, comprimento de raízes e índice de qualidade de Dickson. Houve respostas positivas pela aplicação dos biofertilizantes para todas as variáveis estudadas, destacando-se a aplicação do BIO 2.
\end{abstract}

\section{Use of bio-fertilezers based on amino acids to grow Eucalyptus dunnii seedlings}

\begin{abstract}
The production of forest seedlings in quantity and quality is one of the most important stages for more uniform and productive forest stands establishment. A higher survival and development of seedlings after planting are dependent, among other factors, of their good nutritional status. This study aimed to evaluate the potential use of two bio-fertilizers based on amino acids as initial growth promoters of Eucalyptus dunnii Maiden seedlings, known respectively as "BIO 1" and "BIO 2". The experiment was conducted in a commercial nursery in Imbituva, Parana State, Brazil. It was used a completely randomized design, with three treatments and four replications, with 50 seedlings per replication. The variables evaluated were: plant height, stem diameter, fresh matter weight of shoot and of roots, dry matter weight of shoot and roots, roots length and Dickson quality index (DQI). There were positive responses to bio-fertilizers application for all studied variables, especially when applied BIO 2.
\end{abstract}

\section{Introdução}

As florestas plantadas representam um recurso renovável essencial para atender a crescente demanda global por produtos derivados de biomassa lenhosa (Grattapaglia, 2007; Pijut et al., 2007). Devido a isto, justifica-se a busca por espécies que apresentem madeira de alta qualidade e rápido crescimento (Grattapaglia, 2007; Souza Junior, 2008). Espécies do gênero Eucalyptus têm mostrado grande potencial, considerando-se a versatilidade de uso da madeira para inúmeras aplicações, principalmente para fins industriais, fazendo com que diversas empresas busquem aprimorar seus programas de melhoramento genético, assegurando o estabelecimento de plantios altamente produtivos.

Segundo Gomes \& Paiva (2004) a formação de florestas de alta produtividade é dependente de alguns fatores, como a qualidade genética e fisiológica das sementes e das mudas utilizadas. As mudas de boa 
qualidade são aquelas que apresentam um sistema radicular bem desenvolvido, com a raiz principal sem enovelamento e as raízes secundárias bem distribuídas e agregadas ao substrato, proporcionando um bom desenvolvimento da planta em campo (Mafia et al., 2005). Além do uso de substrato de boa qualidade e manejo da densidade de cultivo, para minimizar o efeito de competição entre as mudas, são também utilizados fertilizantes foliares e outros produtos para estimular o desenvolvimento das plantas em viveiro.

Segundo Gonçalves et al. (2000) os adubos mais recomendados para a produção de mudas florestais são o sulfato de amônio, o superfosfato simples e o cloreto de potássio. No entanto, em razão do crescente aumento nos custos da fertilização química e de seus impactos sobre o ambiente, buscam-se alternativas de fertilização que sejam mais econômicas, eficientes e sustentáveis. A utilização de fontes orgânicas tem sido tradicionalmente subutilizada, destacando-se as excreções animais, compostos sólidos e líquidos (biofertilizantes), adubação verde, tortas vegetais, dentre outras. A substituição paulatina da fertilização química pela orgânica tem sido adotada em diversos viveiros de produção de mudas florestais, além de se tornar uma alternativa interessante para a redução do custo final de produção das mudas.

Tem-se observado maior interesse por parte dos agricultores e viveiristas no manejo nutricional das mudas, onde os fertilizantes orgânicos apresentam um grande potencial a ser utilizado, não apenas por suprirem as exigências nutricionais das plantas, mas também por serem de baixo custo e, sobretudo, por não serem poluentes, contribuindo para a preservação do meio ambiente (Brasil, 1998).

Os biofertilizantes têm sido uma alternativa com potencialidades de uso, já que contém princípios ativos ou agentes orgânicos isentos de substâncias agrotóxicas, capazes de atuar, direta ou indiretamente, sobre o todo ou parte das plantas cultivadas, elevando a sua produtividade, agindo como indutores de resistência, promotores de crescimento e protetores da planta (Alves et al., 2001). Os biofertilizantes têm sido mais empregados no setor agrícola, proporcionando inúmeros benefícios, como o melhor crescimento e desenvolvimento das plantas, estabelecimento do equilíbrio nutricional, preservação das interações biológicas, tornando o ambiente favorável ao desenvolvimento dos microrganismos benéficos do solo, proporcionando maior eficiência nutricional e fotossintética das plantas e com isso, maior produtividade e qualidade dos cultivos (Moraes, 2015).
Sabe-se que os aminoácidos atuam como estimuladores do metabolismo (Frasseto et al., 2010), onde são incorporados rapidamente nas vias metabólicas, estimulando a síntese de proteínas e melhorando o transporte e armazenamento de nitrogênio, este sendo assimilado pelas plantas na forma de nitrato $\left(\mathrm{NO}_{3}{ }^{-}\right) \mathrm{e}$ amônio. $\left(\mathrm{NH}_{4}^{+}\right)$. A passagem de nitrato e amônio através da membrana plasmática das células da epiderme e do córtex da raiz ocorre através de transportadores específicos. Após a sua entrada na célula, o nitrato pode ser reduzido a nitrito pela enzima redutase do nitrato e, após convertido a amônio, no plastídio, pela enzima redutase do nitrito. $\mathrm{O}$ amônio é incorporado em aminoácidos pelas enzimas sintetase da glutamina e sintase do glutamato, formando glutamina e glutamato, dois aminoácidos importantes doadores de $\mathrm{N}$ para numerosas reações celulares, incluindo a biossíntese de aspartato e asparagina (Larsson \& Ingemarsson, 1989). Glutamato, asparagina e aspartato atuam como importantes carreadores de $\mathrm{N}$, tendo papel fundamental na exportação e distribuição deste elemento nas plantas. Estes aminoácidos são também precursores não só das principais famílias de aminoácidos protéicos, como também de outros compostos nitrogenados fundamentais, como a clorofila, os ácidos nucléicos e as poliaminas (Silva et al., 2014).

Dentre os biofertilizantes, destacam-se aqueles produzidos à base de aminoácidos. Estudos relacionados ao uso de aminoácidos evidenciam que quando aplicados via foliar ou radicular promovem o enraizamento, responsável pelo bom desenvolvimento de uma planta (Dotta et al., 2008; Goulart \& Xavier, 2008; Frasseto et al., 2010). Apesar de escassos os trabalhos da aplicação desses biofertilizantes na área florestal, alguns mostram o seu potencial de utilização em viveiros, com aumento expressivo no crescimento e desenvolvimento de mudas florestais (Medeiros et al., 2000; Pichler, 2011; Soares et al., 2014; Mesquita et al., 2015).

O objetivo do presente trabalho consistiu em avaliar os efeitos das aplicações de dois biofertilizantes na produção e qualidade de mudas de Eucalyptus dunnii.

\section{Material e métodos}

O estudo foi conduzido no período de fevereiro a julho de 2015, em viveiro comercial localizado no município de Imbituva, PR. O município está situado na região Centro-Sul do estado do Paraná, com clima predominante, segundo a classificação 
climática de Köppen-Geiger, como mesotérmico, com verões frescos $(\mathrm{Cfb})$, caracterizado pela ocorrência de geadas frequentes no inverno. A cidade situa-se nas coordenadas $25^{\circ} 13^{\prime} 48^{\prime \prime} \mathrm{S}$ e $50^{\circ} 36^{\prime} 16^{\prime \prime} \mathrm{W}$, altitude média de aproximadamente $968 \mathrm{~m}$, com temperatura média máxima de $22{ }^{\circ} \mathrm{C}$, no verão, mínima de $12{ }^{\circ} \mathrm{C}$, no inverno, e precipitação média anual de $1.502 \mathrm{~mm}$ (Prefeitura Municipal de Imbituva, 2015).

Foram utilizadas sementes peletizadas de E. dunnii, adquiridas no próprio viveiro onde o estudo foi desenvolvido. As sementes foram plantadas em tubetes de plástico rígido com capacidade de $50 \mathrm{~cm}^{3}$. O substrato utilizado constituiu-se de turfa agrícola Carolina Soil ${ }^{\mathbb{}}$. Após a semeadura, os tubetes foram acondicionados em casa de sombra por 60 dias, em canteiros suspensos. Após esse período, as mudas foram transferidas para área de pleno sol, ocasião em que se reduziu a densidade das mudas por bandeja, passando para 50\% de ocupação.

Os tratamentos utilizados consistiram da pulverização das mudas com dois biofertilizantes (designados "BIO1" e "BIO2"), ambos à base de aminoácidos, e um tratamento controle.

A formulação do BIO1 foi composta de: $8,8 \%$ de $\mathrm{N} ; 46 \%$ de $\mathrm{P} ; 6,5 \%$ de $\mathrm{K} ; 3,3 \%$ de aminoácidos livres; $19,8 \%$ de matéria orgânica e $15 \%$ de substâncias húmicas (leonardita).

O BIO2 foi composto por: $2,5 \%$ de $\mathrm{N} ; 4 \%$ de $\mathrm{P} ; 4 \%$ de $\mathrm{K}$ e por aminoácidos naturais quelatizados, sendo $5 \%$ de alanina; $16 \%$ de glicina; $1 \%$ de valina; $1,25 \%$ de leucina; $0,55 \%$ de isoleucina; $4,5 \%$ de prolina; $0,65 \%$ de fenilanina; $0,24 \%$ de tirosina; $1,9 \%$ de serina; $0,85 \%$ de trionina; $0,33 \%$ de metionina; $2,4 \%$ de arginina; $0,23 \%$ de histidina; $2,5 \%$ de lisina; $2,4 \%$ de ácido aspártico; 3,6\% de ácido glutâmico; 4,6\% de hidroxiprolina; $0,34 \%$ de hidroxilisina; $0,5 \%$ de $\mathrm{Zn} ; 0,2 \%$ de $\mathrm{B} ; 0,3 \%$ de $\mathrm{Mg}$; $0,1 \%$ de Mo; $0,1 \%$ de Fe; $0,1 \%$ de $\mathrm{Cu} ; 1,5 \%$ de $\mathrm{S} ; 0,25 \%$ de Mn e 15\% de carbono orgânico.

A pulverização das mudas com os biofertilizantes iniciou-se 15 dias após a germinação das sementes. As pulverizações foram realizadas semanalmente, durante todo o período de condução do experimento, até as mudas completarem 90 dias de idade. Cada pulverização foi realizada manualmente com borrifador, sendo aplicados $100 \mathrm{~mL}$ de solução dos biofertilizantes num total de 200 mudas, correspondentes aos respectivos tratamentos.
O modo de preparo das soluções de biofertilizantes ocorreu seguindo-se as concentrações recomendadas pelos fabricantes, em que o BIO1 foi dissolvido em água destilada, em uma solução $0,25 \%(\mathrm{p} / \mathrm{v})$, enquanto o BIO2 foi diluído em água destilada, em uma solução $10 \%(\mathrm{v} / \mathrm{v})$.

$\mathrm{O}$ experimento foi conduzido em delineamento inteiramente casualizado, com três tratamentos e quatro repetições, contendo 50 mudas por repetição, totalizando 200 mudas por tratamento num total de 600 mudas. $\mathrm{O}$ tratamento controle foi constituído por mudas que não receberam a aplicação de biofertilizantes (BIO 0).

As avaliações foram realizadas aos 30 e 60 dias com base na característica altura e aos 90 dias, com base nas características altura, diâmetro do coleto, determinação da matéria fresca e seca da parte aérea e raízes, comprimento das raízes e no índice de qualidade de Dickson (IQD).

A determinação do peso de matéria fresca e seca da parte aérea e das raízes foi realizada com mudas de E. dunnii, aos 90 dias de idade, no Laboratório de Silvicultura da Universidade Estadual do Centro-Oeste, Campus de Irati. As mudas foram cuidadosamente retiradas dos tubetes e destorroadas em água. Em seguida, determinou-se o peso fresco de parte aérea e raízes em balança analítica de precisão. Após, as estruturas foram seccionadas e acondicionadas em embalagens de papel kraft e mantidas em estufa a $65^{\circ} \mathrm{C}$ durante $72 \mathrm{~h}$, até atingirem peso constante, sendo retiradas da estufa para a determinação do peso de matéria seca em balança analítica de precisão.

Calculou-se o índice de qualidade de Dickson para as mudas provenientes de cada tratamento, conforme equação 1 (Dickson et al., 1960).

$$
\mathrm{IQD}=\frac{\text { MST }}{\frac{\text { ALT }}{\text { DIAM }}+\frac{\text { MSPA }}{\text { MSR }}}
$$

Onde: IQD = índice de qualidade de Dickson; alt = altura das mudas $(\mathrm{cm})$; diam = diâmetro de coleto das mudas $(\mathrm{mm})$; MSPA $=$ massa seca da parte aérea $(\mathrm{g})$, englobando caule e folhas; MSR = massa seca de raízes (g); MST = matéria seca total (g).

Foi realizada análise de variância e, quando observada diferenças, as médias comparadas pelo teste de Tukey ao nível de 5\% de significância, utilizando-se o software Assistat ${ }^{\circledR}$ versão 7.7 Beta (Silva \& Azevedo, 2009). 


\section{Resultados e discussão}

Foi observado efeito significativo das pulverizações com os biofertilizantes na altura das mudas de Eucalyptus dunnii, aos 30 dias de idade após a germinação das sementes. As mudas não pulverizadas (BIO 0) apresentaram menor altura comparadas àquelas que receberam o BIO 1. Contudo, não houve diferença estatística quando comparado o $\mathrm{BIO} 0$ ao $\mathrm{BIO} 2$.

$\mathrm{Na}$ segunda avaliação, aos 60 dias de idade, observou-se maior crescimento em altura das mudas pela aplicação dos biofertilizantes (BIO 1 e BIO 2), comparativamente ao tratamento controle. No entanto, a pulverização das mudas com BIO 1 e BIO 2 não diferiu entre biofertilizantes. Aos 90 dias, observou-se que as mudas pulverizadas com o BIO 2 apresentaram maior crescimento em relação as mudas pulverizadas com o BIO 1 e o controle, não sendo observada diferença significativa entre o BIO 1 e o BIO 0 (Figura 1A).

Aos 30 dias, é possível observar que a aplicação do BIO 1 apresentou melhor resultado que os demais tratamentos (Figura 1). Segundo Reis et al. (2008), na ocasião do transplantio das mudas para o campo, a altura desempenha importante papel na sobrevivência e desenvolvimento da planta durante os primeiros anos após o plantio, considerando-se a relação altura/diâmetro do coleto. A maior altura da muda está relacionada com um bom desenvolvimento radicular das plantas, e quando avaliadas junto com o diâmetro de coleto, refletem maior acúmulo de reservas, assegurando resistência e melhor fixação no solo (Sturion \& Antunes, 2000). No entanto, somente ao término das avaliações, aos 90 dias, constatou-se efeito mais pronunciado do BIO 2 no crescimento em altura das mudas. Vale salientar que aos 60 dias, notou-se que as mudas que receberam a aplicação dos biofertilizantes, independentemente de sua composição, tiveram maior crescimento, quando comparadas ao tratamento controle. Todavia, neste período não foi possível detectar diferença estatística entre os biofertilizantes utilizados (BIO 1 e BIO 2). Possivelmente, o melhor desempenho da aplicação do BIO 2, após 90 dias, foi devido à sua composição mais rica, contendo elementos minerais como $\mathrm{N}, \mathrm{P}, \mathrm{S}, \mathrm{K}$ e carbono orgânico, juntamente com uma composição elaborada com de aminoácidos livres (alanina; glicina; valina; leucina; isoleucina; prolina; fenilanina; tirosina; serina; trionina; metionina; arginina; histidina; lisina; ácido aspártico; ácido glutâmico; hidroxiprolina e hidroxilisina). Os elementos minerais N, S e P atuam no arranque inicial do crescimento da parte aérea das plantas (Lima et al., 2011).
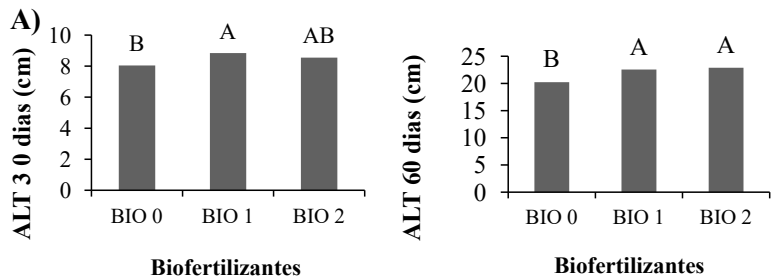

B)
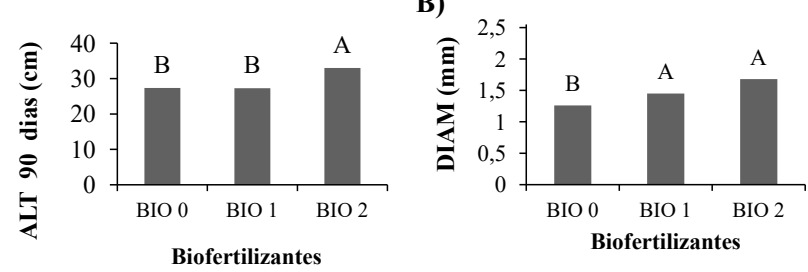

C)

D)
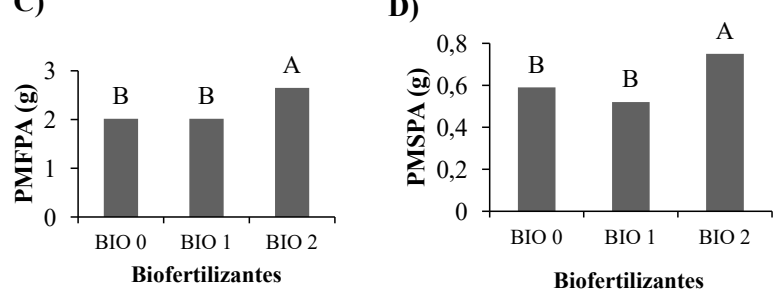

Figura 1. Efeito da aplicação de biofertilizantes na produção e qualidade de mudas de Eucalyptus dunnii, com base nas variáveis: A) altura das mudas (ALT), em $\mathrm{cm}$, avaliadas aos 30, 60 e 90 dias de idade; B) diâmetros das mudas (cm); C) peso de matéria fresca da parte aérea $(\mathrm{g})$; D) peso de matéria seca de parte aérea $(\mathrm{g})$. BIO $0=$ tratamento controle, constituído por mudas não pulverizadas com biofertilizantes; BIO 1 = biofertilizante $1 ; \mathrm{BIO} 2$ = biofertilizante 2 . As médias seguidas pela mesma letra, dentro de uma mesma época de avaliação, não diferem estatisticamente entre si pelo teste de Tukey ao nível de 5\%.

Estudos com outras espécies florestais têm apontado que o uso de biofertilizantes proporcionou maior crescimento em altura das mudas de E. dunnii (Pichler, 2011); Tabeluia avellanedae Lorentz ex Griseb (Polini, 2013), Tectona grandis (Trazzi et al., 2014), Jatropha curcas L. (Shulz et al., 2012) e Peltophorum dubium (Spreng.) Taub (Strauss et al., 2013). No entanto, Soares et al. (2014) observaram redução no crescimento em altura das mudas de Theobroma grandiflorum (Willd. ExSpreng.) Schum em relação à aplicação de biofertilizantes. Para as espécies E. urophylla (Fernandes et al., 2011) e $J$. curcas (Ferreira et al., 2010) não foram observados efeitos significativos da aplicação de biofertilizantes sobre o crescimento das plantas. 
Para a característica diâmetro do coleto, avaliada aos 90 dias, não foram observadas diferenças entre os biofertilizantes BIO 1 e BIO 2, mas as plantas apresentaram maiores diâmetros quando comparadas às do $\mathrm{BIO} 0$ (Figura 1B). Foram observados diâmetros médios do coleto de 2,46 $\mathrm{mm}$ e 2,52 $\mathrm{mm}$, para o BIO 1 e BIO 2, respectivamente. O diâmetro mínimo do coleto, recomendado para mudas de Eucalyptus deve estar entre $2 \mathrm{~mm}$ e 2,5 mm (Sturion et al., 2000; Lopes et al., 2007; Wendling \& Dutra, 2010).

Segundo Gomes \& Paiva (2004) a altura e o diâmetro do coleto, apesar de serem parâmetros importantes, não podem ser avaliados isoladamente para determinar a qualidade das mudas. De forma geral, o diâmetro do coleto é o critério mais observado para indicar a capacidade de sobrevivência da muda em campo (Daniel et al., 1997). Mudas com diâmetro do coleto menor do que o recomendado para a espécie apresentam dificuldade em se manterem eretas após o plantio, podendo resultar em tombamento e morte das plantas (Sturion et al., 2000).

$\mathrm{O}$ incremento em diâmetro do caule da planta, em resposta à aplicação de biofertilizantes, é relatado para diversas espécies florestais, como E. dunnii (Pichler, 2011); T. avellanedae (Polini, 2013); P. dubium (Strauss et al., 2013) e T. grandiflorum (Soares et al., 2014). Em mudas de $J$. curcas, Ferreira et al. (2010) não observaram efeito da aplicação de biofertilizantes em relação a esta variável.

Foi observado efeito significativo da aplicação dos biofertilizantes no peso da matéria fresca (PMFPA) e seca (PMSPA) da parte aérea das mudas de E. dunnii. Houve acréscimo PMFPA quando aplicado o BIO 2 (Figura 1C), destacando-se em relação ao tratamento controle e ao BIO 1.

Aos 90 dias, observou-se efeito significativamente superior no PMSPA pela aplicação do BIO 2, comparado ao BIO 0 e ao BIO 1 (Figura 1D). O incremento da matéria seca de parte aérea após a aplicação de biofertilizantes também foi relatado em mudas de $T$. grandiflorum (Soares et al., 2014) e de Anarcadium occidentale L. (Ramalho, 2010).

A aplicação do biofertilizante Supermagro ${ }^{\circledR}$ em mudas de E. dunnii não surtiu efeito no incremento em matéria fresca da parte aérea (Pichler, 2011), o mesmo sendo observado por Fernandes et al. (2011) nas variáveis crescimento em altura e matéria seca da parte aérea e de raízes, em mudas de dois clones de E. urophylla, com a aplicação do biofertilizante Fert-Bokashi ${ }^{\circledR}$.

O peso de matéria fresca de raízes (PMFR) foi menor para as mudas do controle, quando comparadas àquelas que receberam aplicação do $\mathrm{BIO} 1$ e $\mathrm{BIO} 2$. O BIO 2 proporcionou as maiores médias para este parâmetro em relação ao BIO 1 (Figura 2A). Aos 90 dias o resultado superior do BIO 2 para PMSR foi mais evidente (Figura 2B), não sendo observada diferença para esta variável entre o BIO 1 e o BIO 2. Os resultados obtidos no presente estudo diferem dos relatadospor Fernandes et al. (2011), que não observaram efeito significativo do biofertilizante Fert-Bokashi ${ }^{\circledR}$ no peso de matéria seca de raízes em mudas de dois clones de E. urophylla.
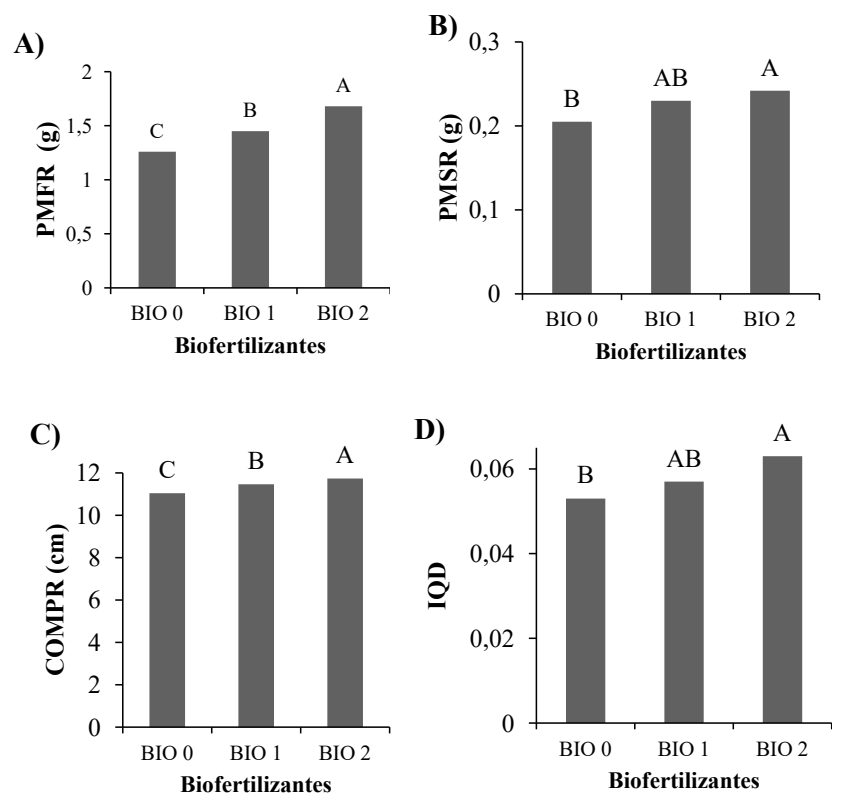

Figura 2. Efeito da aplicação de biofertilizantes na produção e qualidade de mudas de E. dunnii, com base nas variáveis: A) peso de matéria fresca das raízes (g); B) peso de matéria seca das raízes (g); C) comprimento das raízes ( $\mathrm{cm}$ ); D) IQD = índice de qualide de Dickson (g). BIO $0=$ tratamento controle, constituído por mudas não pulverizadas com biofertilizantes; BIO 1 = biofertilizante 1 ; BIO 2 = biofertilizante 2 . As médias seguidas pela mesma letra não diferem estatisticamente entre si pelo teste de Tukey ao nível de 5\%.

A aplicação do BIO 2 proporcionou o melhor resultado para o comprimento de raízes, quando comparado ao controle, evidenciando o maior comprimento médio de raiz, enquanto o menor valor foi observado nas mudas do BIO 0 (Figura 2C).

Observou-se maior qualidade do sistema radicular das mudas de E. dunnii que receberam a aplicação dos biofertilizantes, destacando-se o grande número de 
raízes finas agregadas ao substrato, conforme ilustrado na Figura 3A. A quantidade de raízes finas produzidas é um dos fatores que podem interferir no desempenho inicial das mudas em campo, uma vez que as mudas com maior quantidade de raízes são mais aptas para suportar condições de estresse ambiental, garantindo maiores taxas de crescimento inicial pós-plantio e de sobrevivência (Freitas et al., 2005). A alta densidade de raízes finas aumenta a superfície de contato com o solo, proporcionando à planta maior eficiência em absorver água e nutrientes (Laclau, 2001).

O melhor desenvolvimento radicular das mudas de E. dunnii, submetidas à aplicação dos biofertilizantes, com base no comprimento médio de raízes, pode ser explicado pela presença, na composição química dos produtos utilizados, dos elementos minerais $\mathrm{Zn}$ e B e de aminoácidos. Esses micronutrientes são importantes na formação de tecidos, influenciando no processo de divisão celular, pois ambos estão envolvidos na síntese do ácido indolacético. O B também desempenha papel importante no processo de formação de ácido péctico, precursor da parede celular vegetal (Malavolta, 2006; Fernandes, 2006). A presença de aminoácidos estimula a formação de tecidos, pela indução de mobilização de nutrientes, principalmente $\mathrm{N}$ e S. A absorção direta dos aminoácidos proporciona à planta a não necessidade de metabolizar o $\mathrm{N}$ mineral na forma de nitrato e amônio, fazendo com que possa direcionar maior quantidade de energia para o enraizamento (Caço, 2008). Segundo Mesquita et al. (2015), o aumento do comprimento das raízes pode fortalecer toda a estrutura morfológica das plantas, possibilitando a obtenção de mudas aptas ao transplante em campo em menos tempo.

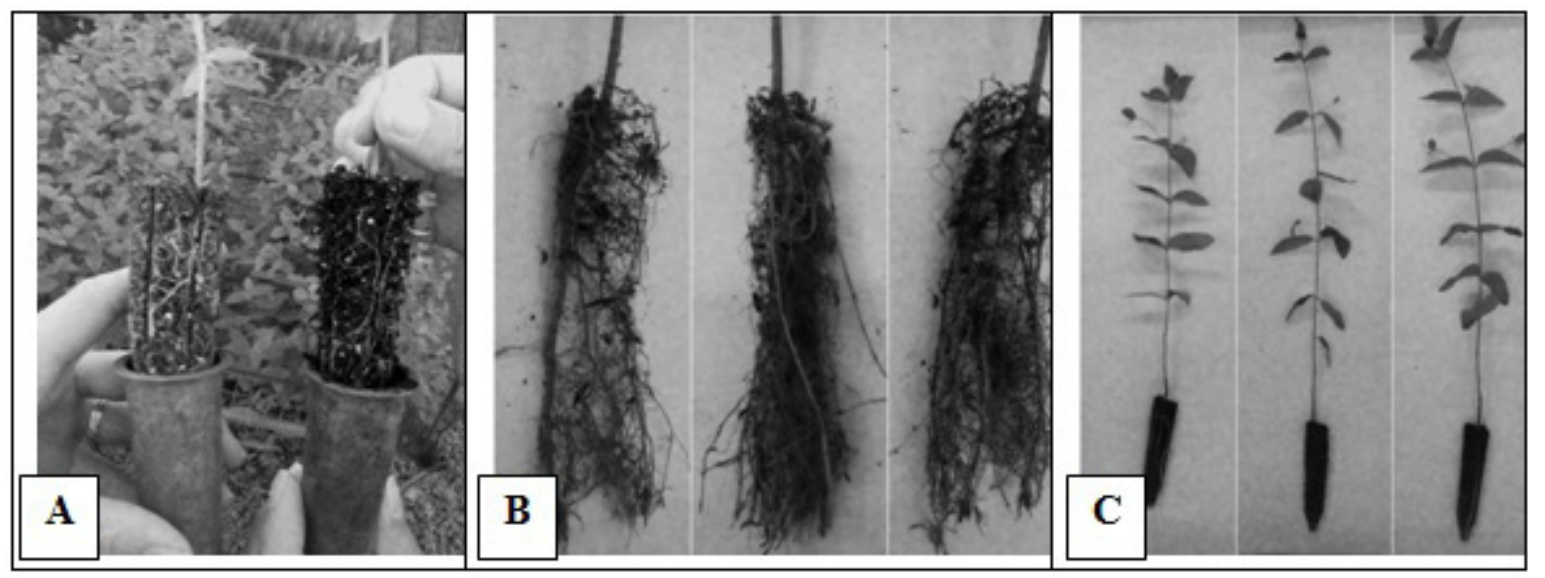

Figura 3. Efeito da aplicação de biofertilizantes na produção e qualidade de mudas de E. dunnii, A) detalhe do sistema radicular de mudas de E. dunnii pulverizada (esquerda) e não pulverizada (direita) com biofertilizante; B) sistema radicular das mudas de $E$. dunnii aos 90 dias, submetidas a pulverizações com biofertilizantes, sendo da esquerda para a direita: controle, BIO 1 e BIO 2; C) mudas de E. dunnii aos 90 dias, Sendo da esquerda para a direita: controle, BIO 1 e BIO 2.

O efeito da aplicação de biofertilizantes a base de aminoácidos no enraizamento de estacas de Sebastiana schottiana Müll. Arg. foi avaliado por Frasseto et al. (2010). Os autores quantificaram a elevação dos teores de carboidratos e substâncias promotoras do enraizamento, atingindo taxas de $60 \%$ de enraizamento das estacas. Goulart \& Xavier (2008) obtiveram aumento nos índices de enraizamento de miniestacas de clones de E. grandis x E. urophylla submetidas à aplicação de diferentes tipos de aminoácidos.

O uso de biofertilizante bovino, rico em substâncias húmicas, na produção de mudas de Azadirachta indica
L. resultou no incremento de $26,88 \%$ no crescimento radicular das plantas (Mesquita et al., 2015).

Resultados contraditórios aos obtidos no presente trabalho, em relação ao efeito dos biofertilizantes no crescimento radicular foram relatados por Ferreira et al. (2010) ao testarem dosagens de biofertilizante no crescimento inicial das mudas de $J$. curcas. Estes autores relataram que a aplicação do biofertilizante não influenciou significativamente nas variáveis área foliar, volume e comprimento radicular.

Foram obtidos maiores valores do IQD com a aplicação do BIO 2 (Figura 2D). A aplicação do BIO 
1 não diferiu estaticamente dos demais tratamentos avaliados. Mudas que não receberam a aplicação de biofertilizantes apresentaram o menor IQD. Este índice pode variar em função da espécie, do manejo nutricional das mudas no viveiro, do tipo e proporção do substrato, do volume do recipiente e, principalmente, de acordo com a idade em que a muda for avaliada (Gomes et al., 2013). Caldeira et al. (2012) apontaram o IQD como bom indicador de qualidade de mudas, tendo em vista que este índice considera, para seu cálculo, a robustez (relação altura/diâmetro do coleto) e o equilíbrio da distribuição da biomassa (relação matéria seca da parte aérea/matéria seca de raízes), ponderando os resultados das várias características morfológicas importantes utilizadas para a avaliação da qualidade das mudas. Desta forma, quanto maior o valor de IQD, melhor é a qualidade da muda produzida.

A aplicação de dosagens de biofertilizante Supermagro $^{\circledR}$, em mudas de E. dunnii, em diferentes intervalos de tempo, não influenciou os valores de IQD obtidos. Apesar disto, observou-se que o intervalo de aplicação de 28 dias proporcionou maior valor de IQD das plantas (Pichler, 2011).

No presente trabalho, as mudas pulverizadas com biofertilizantes apresentaram um IQD maior do que as plantas do tratamento controle, comprovando serem mudas de melhor qualidade, onde em todos os parâmetros avaliados (altura, diâmetro de coleto, peso de matéria fresca e seca de raízes e de parte aérea, comprimento de raízes e IQD) mostraram desempenho superior (Figuras 3B e 3C).

\section{Conclusão}

Ao final de 90 dias, a aplicação dos biofertilizantes proporcionou melhoria significativa da qualidade das mudas de Eucalyptus dunnii. A aplicação do biofertilizante 2 resultou no maior incremento das variáveis altura, peso de matéria fresca e seca da parte aérea, peso de matéria fresca e comprimento de raízes.

\section{Referências}

Alves S. B. et al. Trofobiose e microrganismos na proteção de plantas. Biotecnologia Ciência \& Desenvolvimento, n. 21, p. 16-19, 2001.
Brasil. Lei $\mathbf{n}^{\mathbf{0}} \mathbf{9 . 6 0 5}$, de 12 de fevereiro de 1998. Dispõe sobre as sanções penais e administrativas derivadas de condutas e atividades lesivas ao meio ambiente, e dá outras providências. Publicada originalmente no Diário Oficial [da] República Federativa do Brasil em 13 fev. 1998, retificado em 17 fev. 1998. Disponível em: <http:// www.planalto.gov.br/ccivil_03/leis/L9605.htm>. Acesso em: 21 maio 2016

Caldeira, M. V. W. et al. Biossólido na composição de substrato para a produção de mudas de Tectona grandis. Floresta, v. 42, n. 1, p. 77-84, 2012. DOI: 10.5380/rf.v42i1.26302.

Caço, J. Aminoácidos: nutrientes orgânicos. Olhão: Grupo Hubel, [2008]. Disponível em: <http:// http://www.hubel.pt/fotos/artec/ hv_aminoacidos_1288022939.pdf>.Acesso em: 20 maio 2015

Daniel, O. et al. Aplicação de fósforo em mudas de Acaciamangium WILLD. Revista Árvore, v. 21, n. 2, p. 163-168, 1997.

Dickson, A. et al. Quality appraisal of white spruce and white pine seedling stock in nurseries. Forest Chronicle, v. 36, p. 10-13, 1960. DOI: $10.5558 / \mathrm{tfc} 36010-1$.

Dotta, J. H. et al. Micronutrientes e Aminoácidos no desenvolvimento em tomateiro cultivado em rizotron. Desafios para o uso do solo com eficiência e qualidade ambiental. In: REUNIÃO BRASILEIRA DE FERTILIDADE DO SOLO E NUTRIÇÃO DE PLANTAS, 28.; REUNIÃO BRASILEIRA SOBRE MICORRIZAS, 12.; SIMPÓSIO BRASILEIRO DE MICROBIOLOGIA DO SOLO, 10.; REUNIÃO BRASILEIRA DE BIOLOGIA DO SOLO, 7., 2008, Londrina. FertiBio 2008: desafios para o uso do solo com eficiência e qualidade ambiental: anais. Londrina: Sociedade Brasileira de Ciência do Solo; Embrapa Soja; Universidade Estadual de Londrina, 2008.

Fernandes, M. S. Nutrição mineral de plantas. Viçosa, MG: Sociedade Brasileira de Solos, 2006. 432 p.

Fernandes, S. J. O. et al. Sobrevivência e crescimento de mudas clonais de eucalipto em resposta à aplicação de fertilizante orgânico. Cerne, v. 17, n. 4, p. 601-606, 2011

Ferreira, A. S. et al. Crescimento de mudas de pinhão manso (Jatropha curcas L.) sob diferentes dosagens de biofertilizante. In: CONGRESSO BRASILEIRO DE MAMONA, 4.; SIMPÓSIO INTERNACIONAL DE OLEAGINOSAS ENERGÉTICAS, 1., 2010, João Pessoa. Inclusão social e energia: anais. Campina Grande: Embrapa Algodão, 2010. p. 524.

Frasseto E. G. et al. Enraizamento de estacas de Sebastiania schottiana Müll. Arg. Ciência Rural, v. 40, n. 12, p. 2505-2509, 2010. DOI: $10.1590 / \mathrm{S} 0103-84782010005000199$.

Freitas, T. A. S. et al. Desempenho radicular de mudas de eucalipto produzidas em diferentes recipientes e substratos. Revista Árvore, v. 29, n. 6, p. 853-861, 2005. DOI: 10.1590/S010067622005000600003.

Gomes, D. R. et al. Lodo de esgoto como substrato para a produção de mudas de Tectona grandis L. Cerne, v. 19, n. 1, p. 123-131, 2013. DOI: 10.1590/S0104-77602013000100015.

Gomes, J. M. \& Paiva, H. N. Viveiros florestais (propagação sexuada). Viçosa, MG: Ed. da UFV, 2004. (Caderno didático, 72). 
Gonçalves, J. L. M. \& Benedetti, V. Nutrição e fertilização florestal. Piracicaba: IPEF, 2000. 427 p.

Goulart, B. P. \& Xavier, A. Efeito do tempo de armazenamento de miniestacas no enraizamento de clones de Eucalyptus grandis $\mathrm{x}$ E. urophylla. Revista Árvore, v. 32, n. 4, p. 671-677, 2008. DOI: 10.1590/S0100-67622008000400008.

Grattapaglia, D. Aplicações operacionais de marcadores moleculares. In: Borém, A. (Ed.). Biotecnologia florestal. Viçosa, MG: Suprema, 2007. p. $175-200$.

Larsson, C. M. \& Ingemarsson, B. Molecular aspects of nitrate uptake in higher plants. In: Wray, J. L. \& Kinghorn, J. R. Molecular and genetics aspects of nitrate assimilation. Oxford: Oxford Science, 1989. p. 3-14.

Laclau, J. P. Spatial distribution of Eucalyptus roots in a deep sandy soil in the Congo: relationships with the ability of the stand to take up water and nutrients. Tree Physiology, v. 21, p. 129-136, 2001.

Lima, R. L. S. et al. Atributos químicos de substrato de composto de lixo orgânico. Revista Brasileira de Engenharia Agrícola e Ambiental, v. 15, n. 2, p. 185-192, 2011.

Lopes, J. L. W. et al. Qualidade de mudas de eucalipto produzidas sob diferentes lâminas de irrigação e dois tipos de subtrato. Revista Árvore, v. 31, n. 5, 2007. DOI: 10.1590/S0100-67622007000500007.

Mafia, R. G. et al. Crescimento de mudas e produtividade de minijardins clonais de eucalipto tratados com rizobactérias selecionadas. Revista Árvores, v. 29, n. 6, p. 843-851, 2005. DOI: 10.1590/S0100-67622005000600002.

Malavolta, E. Manual de nutrição mineral de plantas. São Paulo: Ceres, 2006. $638 \mathrm{p}$.

Medeiros, M. B. et al. Efeito residual de biofertilizante líquido e Beauveria bassiana sobre o ácaro Tetrany chusurticae. Arquivos do Instituto biológico, v. 67, supl., p. 106, 2000.

Mesquita, F. O. et al. Formação de mudas de nim sob a salinidade da água, biofertilizante e drenagem do solo. Irriga, v. 20, n. 2, p. 193-203, 2015.

Moraes, J. G. V. Biofertilizantes: identificação das barreiras regulatórias e propostas para viabilizar esse insumo agrícola. 2015. 81 f. Dissertação (Mestrado em Agronegócio) - Escola de Economia de São Paulo da Fundação Getúlio Vargas, São Paulo.

Pichler, M. E. B. Avaliação do biofertilizante supermagro na produção de mudas de Eucalyptus dunnii Maiden. $2011.83 \mathrm{f}$. Dissertação (Mestrado em Ciências Florestais) - Universidade Estadual do Centro-Oeste do Paraná, Irati.

Pijut, P. M. et al. Technological advances in temperate hardwood tree improvement including breeding and molecular marker applications. In Vitro Cellular \& Developmental Biology: Plant, v. 43, n. 4, p. 283-303, 2007. DOI: 10.1007/s11627-007-9026-9.

Polini, D. M. S. S. et al. Produção de mudas de ipê roxo (Tabeluia avellanedae) em substrato moinha de carvão com biofertilizante e adubo mineral. In: SIMPÓSIO INTERNACIONAL SOBRE GERENCIAMENTO DE RESÍDUOS AGROPECUÁRIOS E AGroIndUStriais, 3., 2013, São Pedro. Anais... São Pedro: SBERA, 2013. Pen drive.
Prefeitura Municipal de Imbituva. Aspectos naturais e geográficos. Disponível em: $<$ http://imbituva.pr.gov.br/index.php?sessao=648b6 40548nc64\&id=1545>. Acesso em: 20 mar. 2015

Ramalho, J. T. Crescimento de mudas de cajueiro sob diferentes doses de biofertilizante de origem anima. In: CONGRESSO CEARENSE DE AGROECOLOGIA, 2, 2010, Juazeiro do Norte, CE. Anais... Juazeiro do Norte: UFC, 2010. p. 1-4.

Reis, E. R. et al. Período de permanência de mudas de Eucalyptus grandis em viveiro baseado em parâmetros morfológicos. Revista Árvore, v. 32, n. 5, p. 809-814, 2008. DOI: 10.1590/S010067622008000500004.

Schulz, D. G. et al. Crescimento inicial de pinhão manso em função de fontes e doses de adubos orgânicos. Ciência e Agrotecnologia, v. 36, n. 6, p. 615-623, 2012. DOI: 10.1590/S1413-70542012000600003.

Silva, F. A. S. \& Azevedo, C. A. V. Principal components analysis in the software Assistat-Statistical Attendance. In: WORLD CONGRESS OF COMPUTERS IN AGRICULTURE AND NATURAL RESOURCES, 7, 2009, Reno. St. Joseph: American Society of Agricultural and Biological Engineers, 2009.

Silva, J. G. de et al. Efeito da deposição atmosférica na ecofisiologia do uso de nitrogênio em espécies arbóreas da Floresta Ombrófila Densa, Caraguatatuba, SP. In: WORKSHOP INTERAÇÕES PLANTA-AR-SOLO EM ECOSSISTEMAS ANTROPIZADOS, São Paulo., 2014. [Trabalhos apresentados]. São Paulo: Instituto de Botânica, 2014.

Soares, E. M. R. et al. Emergência e desenvolvimento inicial de plântula de cupuaçu em substrato enriquecido com biofertilizante. Revista Brasileira de Agroecologia, v. 9, n. 1, p. 176-184, 2014.

Souza Junior, L. et al. Miniestaquia de Grevillea robusta A. Cunn. A partir de propágulos juvenis. Ciência Florestal, v. 18, n. 4, . p. 455-460.2008. DOI: 10.5902/19805098429.

Strauss, L. F. et al. Influência de biofertilizante no crescimento de mudas de Peltophorum dubium (Canafístula) com diferentes doses, 2001. In: SIMPÓSIO BRASILEIRO DE RECURSOS HÍDRICOS, 20., 2013, Bento Gonçalves, RS. Anais... Bento Gonçalves, RS: Associação Brasileira de Recursos Hídricos, 2013.

Sturion, J. A. \& Antunes, B. M. A. Produção de mudas de espécies florestais. In: Galvão, A. P. M. (Ed.). Reflorestamento de propriedades rurais para fins produtivos e ambientais. Colombo: Embrapa Florestas, 2000. p. 125-150.

Sturion, J. A. et al. Produção de mudas de espécies de rápido crescimento por pequenos produtores. Colombo: Embrapa Florestas, 2000. 20 p. (Embrapa Florestas. Circular Técnica, 37).

Trazzi, P. A. et al. Crescimento e nutrição de mudas de Tenctona grandis produzidas em subtrato orgânicos. Scientia Forestalis, v. 42, n. 101, p. 49-56, mar. 2014.

Wendling, I. \& Dutra, L. F. Produção de mudas de eucalipto por sementes. In: WENDLING, I.; DUTRA, L. F. Produção de mudas de eucalipto. Brasília, DF: Embrapa Informações Tecnológicas; Colombo: Embrapa Florestas, 2010. p. 13- 47. 